BULLETIN Bulletin hispanique

HISPANIQUE Université Michel de Montaigne Bordeaux

117-1 | 2015

Les poètes des rhéteurs

\title{
El Góngora de Gracián (con Tesauro al fondo)
}

\section{Giuseppe Mazzocchi}

\section{(2) OpenEdition}

Journals

Edición electrónica

URL: https://journals.openedition.org/bulletinhispanique/3798

DOI: 10.4000/bulletinhispanique.3798

ISSN: 1775-3821

\section{Editor}

Presses universitaires de Bordeaux

\section{Edición impresa}

Fecha de publicación: 1 junio 2015

Paginación: 159-170

ISBN: 979-10-300-0174-7

ISSN: 0007-4640

\section{Referencia electrónica}

Giuseppe Mazzocchi, «El Góngora de Gracián (con Tesauro al fondo)», Bulletin hispanique [En línea], 117-1 | 2015, Publicado el 01 junio 2018, consultado el 12 febrero 2022. URL: http://

journals.openedition.org/bulletinhispanique/3798; DOI: https://doi.org/10.4000/bulletinhispanique. 3798 


\title{
El Góngora de Gracián (con Tesauro al fondo)
}

\author{
Giuseppe Mazzocchi \\ Università di Pavia
}

L'interprétation que donne Gracián de Góngora dans l'Agudeza y arte de ingenio est ici remise en question à la lumière d'une relecture croisée du traité et du Cannocchiale aristotelico de Tesauro. Il résulte de la double approche, rhétorique de l'Italien et philosophique de Gracián, que ce dernier ne pouvait accepter théoriquement la proposition révolutionnaire de Góngora.

Mots-clés: Góngora, Gracián, Tesauro, Rhétorique baroque.

Se vuelve a considerar la interpretación de Góngora dada por Gracián en la Agudeza $y$ arte de ingenio a la luz de una renovada lectura paralela del tratado y del Cannocchiale aristotelico de Tesauro. Se evidencia así la perspectiva retórica del italiano y la filosófica de Gracián, que le impide aceptar teóricamente la revolucionaria propuesta de Góngora.

Palabras claves: Góngora, Gracián, Tesauro, Retórica barroca.

The interpretation given by Gracián of Gongora in his Agudeza y arte de inenio, is questioned in the light of a parallel rereading of Tesauro's Canocchiale aristotelico. The different approaches of the two treatises, rhetorical in the case of Tesauro, philosophical in that of Gracián, explain why it was impossible for the latter to accept theoretically the revolutionary programme of Gongora.

Keywords: Góngora, Gracián, Tesauro, Baroque Rhetoric.

$\mathrm{E}^{1}$ 1 tema de la presencia de Góngora en Gracián, y de la interpretación que el gran jesuita dio del mayor poeta barroco, ha atraído tradicionalmente el interés de los especialistas, aunque Pérez Lasheras (2001: 71-88), en su utilísimo estado de la cuestión, no deja de observar que necesita todavía una consideración detenida. El importante número de citas de Góngora, ya a partir de las del Arte, para llegar a la setentena de la Agudeza, explica, evidentemente, 
el éxito del enfoque: Góngora es, con Marcial, el poeta más citado en la obra clave de la tratadística retórica barroca. Y la apreciación general del teórico de la agudeza es muy positiva: «Fue este culto poeta cisne en los concentos, águila en los conceptos; en toda especie de agudeza eminente, pero en esta de contraproporciones consistió el triunfo de su grande ingenio: vense sus obras entretejidas desta sutileza» (Gracián 2004: V, 60) ${ }^{1}$.

A partir del interrogante de fondo (¿cómo leyó Gracián a Góngora?) el análisis se desarrolló, en primer lugar, dentro de la línea de una contraposición, por cierto esquemática y superada, entre culteranismo y conceptismo. La idea que ha primado es la de un Gracián conceptista que nos ofrece una lectura limitada y orientada de Góngora, lo cual explicaría, en primer lugar, el escaso interés por los poemas mayores. En efecto, para las Soledades solo tenemos (en la Agudeza, no en el Arte) una apreciación genérica en la que se acoplan al Polifemo:

Pero vengamos ya al estilo aliñado, que tiene más de ingenio que de juicio; atiende a la frase relevante, al modo de decir florido. Fue fénix dél, no tanto por primero, pues ya en el latín Apuleyo y en el español don Luis Carrillo lo platicaron, cuanto porque lo remontó a su mayor punto, don Luis de Góngora, especialmente en su Polifemo y Soledades. Algunos le han querido seguir, como Ícaros a Dédalos; cógenle algunas palabras de las más sonoras, y aun frases de las más sobresalientes -como el que imitó el defecto de torcer la boca del rey de Nápoles-; incúlcanlas muchas veces, de modo que a cuatro o seis voces reducen su cultura. ¡Oh qué bien los nota el juicioso Bartolomé Leonardo!: "Con mármoles de nobles inscripciones, / (teatro un tiempo y aras) en Sagunto, / fabrican hoy tabernas y mesones» (Gracián 2004: LXII, 639-640).

Monge (1966: 377) observa correctamente que lo que ataca Gracián en los imitadores es la reducción del gongorismo a mero ornatus, sin una base conceptual:

a Góngora se le cita muchas veces con elogio porque unió la agudeza «al modo de decir florido». Pero se ataca a aquellos imitadores que no fueron «agudos» a la vez que «cultos». Así pues, la poesía «culta» merecerá aplauso cuando una el artificio retórico a la agudeza de los conceptos. Pero será también vituperable en la medida en que (como hicieron muchos de los continuadores de Góngora) sacrifique la agudeza en beneficio del ornamento.

A las ya aducidas hay que añadir dos citas textuales del Polifemo: en el discurso XIX (Gracián 2004: 206), a propósito del encarecimiento por disminución, se comenta la octava 18 del Polifemo («Sicilia, en cuanto oculta, en cuanto ofrece...»); y en el discurso XLVIII (p. 502), sobre la adjetivación metafórica, se cita el dístico final de la octava 9 de la misma fábula: «los bueyes a su albergue reducía, / pisando la dudosa luz del día».

Gracián expresa en el tratado una opinión que habría que contrastar con la del Criticón, y que nos consigna una posible evolución (Romera Navarro,

1. El juicio figura ya en términos prácticamente idénticos en el Arte. Todas las citas corresponden a la edición de Peralta, Ayala y Andreu (Gracián, 2004). 
Correa Calderón, Dehennin) de su pensamiento crítico; o, como apuntaron otros críticos, más bien hace aflorar reservas que debieron de ser constantes: «Si en este culto plectro cordobés hubiera correspondido la moral enseńanza a la heroica composición, los asuntos graves a la cultura de su estilo, la materia a la bizarría del verso, a la sutileza de sus conceptos, no digo yo de marfil, pero de un finísimo diamante formarse su concha» (Gracián 2000: 429-430).

Posiblemente sea el carácter extremo de los poemas mayores, y su apartamiento de cualquier preocupación moral lo que produjo el distanciamiento de Gracián. Ciertos excesos de las Soledades y el Polifemo, además, estaban lejos de la lectura conceptista de Gracián, por quien, lo observa Dehennin, jamás veremos citadas las maravillas de endecasílabos como "púrpura nevada o nieve roja», sino recreado, me permito añadir, su esqueleto retórico ${ }^{2}$. Toda la lectura de Góngora por parte de Gracián estaría orientada por el conceptismo, y se resentiría de una limitación moralista, aspecto este realzado sobre todo por Rozas (1986: 191-200). Esto, por supuesto, dentro de un gongorismo inevitable, que a la altura de mediados de siglo no puede sorprender. Incluso desde perspectivas diferentes se llega a la misma conclusión. Giulia Poggi (1986: 83-122) habla, para Góngora, de un misterio ontológico, no semántico (el adjetivo semántico se lo reserva la crítica a Gracián). Y otra hispanista italiana (Cancelliere 2004: 293), en un ensayo no menos importante, contrapone un Góngora mental, solo en apariencia realista, a un Gracián que no renuncia al nexo entre palabras y cosas, que no comprende que las formas son importantes, que, al contrario de Góngora, no acepta ni lo icónico ni lo metafórico. En otras palabras, Gracián manifiesta, según estas interpretaciones, una radical incomprensión de la novedad y de la amplitud de miras del poeta de Córdoba.

Quizás un asedio un tanto formalista al problema pueda arrojar un poco de claridad, para que otro cante con mejor plectro. Lo primero que habría que considerar posiblemente sea la construcción del tratado como tal, la recopilación de autoridades y citas de relleno, y sin duda escogidas en parte al azar. Es lo que la tratadística barroca nos muestra constantemente, incluso en campos ajenos a la retórica, donde el fenómeno puede casi parecer obvio. Como ejemplo de una tendencia general, que a menudo olvidamos, reduciéndonos a ver las obras del pensamiento barroco mucho menos como el fruto de una dispositio arquitectónica determinada y atenta que del libre juego del pensamiento, podemos considerar la Guía espiritual de Molinos: según nos muestran los fundamentales papeles de la Biblioteca Apostolica Vaticana que estudió Andreina Rita (2005: 99-116), la princeps romana de 1675 presenta un alarde de autoridades espirituales que faltaban en la primera redacción manuscrita, y que fueron ańadidas por sugerencia de un anónimo lector italiano, a quien evidentemente le preocupaba que una obra tan innovadora careciese del suficiente respaldo de autoridades irrebatibles. Con razón Aurora Egido («Introducción» a Gracián 2005: 20) ha insistido en lo fundamental que debió ser, para la construcción del tratado, el cartapacio de citas sacadas de lecturas

2. Véase la doble hipálage del fragmento citado en la nota 7. 
personales que Gracián, según la práctica del tiempo, hubo de formar ya a partir de sus años de estudiante. Todo esto explicaría la casualidad de las citas: en la selección de los ejemplos, los libros más al alcance de la mano se imponen. A lo mejor a partir de bibliotecas de fácil acceso para él, como la de Lastanosa. Creo que no podemos explicar de otro modo la predilección de nuestro autor por el Pastor fido de Guarino, mientras que en el caso de Las Firmezas de Isabela, la obra de Góngora más citada, se observa que Gracián no parece aprovechar la riqueza de perspectivas lingüísticas que el texto teatral le brinda: la relación entre situación y agudeza que ofrece la comedia -es decir, los actos de habla (para emplear un término anacrónico) - no parece aquí interesarle a Gracián, a pesar de lo debatido en varios discursos. Y es buena prueba de ello el nulo interés que demuestra por las piezas dramáticas de Lope y Calderón.

Otro aspecto a considerar, que corrige en parte la casualidad recién aludida, es la economía de cada discurso. Como en el Arte, hay también una tendencia a repetir su estructura ${ }^{3}$, así como a repartir las citas de determinados autores, con un equilibrio constante: Marcial, los aragoneses y Góngora (normalmente en este orden) son los que tienden a figurar en cada discurso (aunque don Luis falte en varios). De igual modo, puede ser interesante el contraste entre Arte y Agudeza. En la Agudeza figuran muchos fragmentos gongorinos por primera vez; pero lo más interesante es la tendencia acentuada a ampliar el comentario, a añadir el juicio, sin dejar sola la cita. El proceso es esencial, y no rige solo para Góngora; por cierto, no deja de expresar una relevante tensión estilística; sin embargo es evidente que no repercute en la interpretación del poeta. Véanse unos ejemplos de este comportamiento ${ }^{4}$ :

1) (Sobre el soneto Menos solicitó veloz saeta)

Es gran fruto de una semejanza destas el desengaño y moralidad. Raro fue este soneto de don Luis de Góngora, y nunca bastantemente apreciado (Gracián 2010: XI, 192).

Todo el fruto de una semejanza destas, viene a ser el desengańo y la moral enseñanza. Sea corona desta agudeza este precioso soneto, compuesto de las mismas aremas de oro de Hipocrene, en vez de sílabas. Don Luis de Góngora, a la brevedad de la vida ... (Gracián 2004: XII, 147).

2) Fingir la malicia en las cosas inanimadas es también sutileza. Assí dixo don Luis de Góngora

Que no crean a las aguas

sus vellos ojos serenos,

3. Cf. Gracián $\left(2010^{2}: 49\right)$ : «Desde el discurso IV hasta el XLI, Gracián va a ofrecer una amplia variedad de tipos de agudeza o de conceptos, según un método expositivo bastante estable. En buena parte de ellos, el esquema que emplea no parece ser el mismo, pero es similar: arranca siempre con una reflexión de carácter general, que podría servir de definición, a la que suele seguir una explicación, encabezada por una fórmula del tipo "Consiste el artificio". Después, puede distinguir dos partes claramente diferenciadas del fenómeno conceptuoso (ya sea agudeza o concepto): una que tiene que ver con el fundamento y otra con el artificio (si se quiere, con la materia y la forma)».

4. La cita de la Agudeza sigue a la del Arte. Las citas del Arte de ingenio proceden de la edición de Blanco cit. en la nota anterior. 
pues no la han lisonjeado

quando la murmuran luego (Gracián 2010: XIX, 242).

Fíngese el artificio malicioso en las cosas inanimadas con mayor gracia atribuyéndoles la afectación. Elegantemente dijo Luis Vélez en su romance del invierno [...]. Añadió don Luis de Góngora la hermosa contraposición, ya de lisonja, ya de burla a la fingida crisi, diciendo:

Que no crean a las aguas

sus bellos ojos serenos,

pues no la han lisonjeado

cuando la murmuran luego.

Valiose de las dos contingencias especiales y correspondientes entre sí, ya del representar como espejo sus cristales detenidos, ya de murmurar las corrientes (Gracián 2004: XXVI, 298).

3) Por encarecimiento usa muchas vezes desas dudas don Luis de Góngora.

Tan valiente sobre hermosa... (Gracián 2010: XLI, 370).

Por encarecimiento usa muchas veces destas ponderadas dudas don Luis de Góngora, con mucha arte:

Tan valiente sobre hermosa.

que en duda están las heridas,

a cuál reconozcan más,

a su espada, o a su vista (Gracián 2004: XLIV, 477).

4) Hállase correspondencia y proporción en las paronomasias como esta de don Luis de Góngora

Este que Babia al mundo oy ha ofrecido... (Gracián 2010: XXV, 276).

Hay también correspondencia y proporción entre las dicciones y sus significados; correspondiéndose la una a la otra, como se logra en este panegírico de tan gran poeta a tan gran historiador, don Luis de Góngora a Luis de Babia:

Este que Babia al mundo hoy ha ofrecido... (Gracián 2004: XXXII, 374).

Como se ve, la crítica se hace más enfática, hiperbólica si se quiere, con más participación. Pero el mayor detenimiento lleva a un juicio más cálido, pero no a una interpretación más detallada o profunda; es oportuno que retengamos el axioma de que juzgar no es lo mismo que interpretar; apreciar no supone que se haga explícito el juicio positivo en sus razones. La lectura de Góngora que lleva adelante Gracián es fundamentalmente apreciativa, y en efecto observamos la repetición de los mismos clichés. Así, por ejemplo, es importante el agrado («agradable correspondencia», "salida agradable», «agradable repetición»); el momento ponderativo ("gran concepto») es también muy común; y añádanse iuncturae como "grave sentencia», "célebre soneto», "tan gentil agudeza», «valiente principio», «extremada sutileza» etcétera. Gracián, lo notó ya una lectora de olfato muy fino como Dehennin (1980: 618), emite juicios positivos, pero no explica, a pesar de ser Góngora el poeta español posiblemente más necesitado de glosa. Muchas veces nos quedamos tan cortos que no entendemos la razón de la cita. ¿Realmente la explicación consigue aclarar su presencia? 
Aquí llegamos al punto de lo que pretende ser la Agudeza. Lo misterioso del concepto, de su esencia, impide de hecho una explicación clara y unívoca. También nos podemos cuestionar el valor pedagógico de la obscuridad ${ }^{5}$ al lector se le piden agudeza y esfuerzo para comprender los textos, mejor dicho las citas fragmentarias (en la mayoría de los casos de esto se trata) que se le brindan. Por otra parte, es también evidente que el texto de supuesta aclaración, el que acompaña a la cita y debería justificar y aclarar su presencia, no tiene una función subalterna respecto a la cita misma.

¿Cuál es el estilo de la Agudeza? Se trata de un tema poco tocado, y en el que habría que profundizar, tal como se examinó (pienso por ejemplo en los estudios de Senabre, 1979: 57-67 $)$ la aplicación de la agudeza en otras obras de Gracián. En el discurso LXII Gracián no deja de indicar ejemplos relevantes de estilo en la prosa histórica (Malvezzi) ${ }^{7}$ o demostrativa (Paravicino) ${ }^{8}$, lo cual hace que también su propio tratado, implícitamente, se nos presente como un ejemplo de estilo, entiéndase de estilo agudo, que el lector está llamado a desentrañar al igual que las citas poéticas que en él figuran.

Por otra parte, si tenemos en cuenta la naturaleza del libro y la función que las citas adquieren en él, es evidente que nos las habemos con un tratado que no aspira a la interpretación cabal de la obra (o del poeta), sino a la educación del lector mediante un sinfín de citas iluminadoras. Damos así con el fondo del fragmentarismo de la Agudeza, para el cual no representan ninguna excepción los sonetos, con frecuencia citados de forma integral: en los poemas escritos en esta forma métrica lo que le interesa a Gracián es normalmente la agudeza final, que se puede apreciar solo leyendo el texto de forma total. La preferencia acusada de Gracián por los romances de Góngora tiene naturalmente una explicación práctica, al permitir esta especie textual captar la agudeza en breve:

ciò che importa notare è come, al di là delle soluzioni cui Góngora adattò il genere, Gracián colga in esso, più che nei sonetti, una specifica densità concettuale, un intersecarsi di artifici e meccanismi ingegnosi che ben si modella sul ritmo casistico del trattato, là dove invece la citazione del sonetto tende a rallentarlo e interromperlo (Poggi 1986: 105) ${ }^{9}$.

5. Como fondo del examen de todo este aspecto hay que tomar el libro de Roses Lozano (1994).

6. Véase también la introducción de Correa Calderón (1971: I, XLIX-LIX) a su edición del Criticón. Me gustaría, en efecto, que para Gracián dispusiéramos de una lectura estilística del tratado como la que firmó el Padre Pozzi (1953: 25-39) para el Cannocchiale aristotelico de Tesauro. Creo que dicho análisis podría ser útil para comprender mejor la diferencia entre las dos obras de las que me ocupo en este trabajo.

7. «El marqués Virgilio Malvezzi, merecedor de tan suprema clase, junta el estilo sentencioso de los filósofos con el crítico de los hstoriadores, y hace un mixto admirado: parece un Séneca que historia y un Valerio que filosofa» (Gracián 2004: 639).

8. «En la prosa fue igual suyo el agradable Hortensio; juntó lo ingenioso del pensar con lo bizarro del decir; es más admirable que imitable» (Gracián 2004: 640).

9. Que es la respuesta a la pregunta que se plantea al final de su análisis Carreño (1989). 
Pero lo que tiene que quedar claro es que la Agudeza, en contra de lo que a veces se ha dicho, no es una antología (como puede serlo, sorprendentemente, un tratado de métrica como la Rhytmica de Caramuel, impresa en 1665), sino una colección de citas finalizada. Esto supone, por cierto, el aprovechamiento servil de los textos, pero no que se ahonde en su interpretación.

Por todo lo dicho, e incluso para comprender mejor el planteamiento que de Góngora hace Gracián, creo que es fundamental volver a leer en paralelo la Agudeza y el Cannocchiale aristotelico de Tesauro, más allá de las observaciones, clásicas ya, de García Berrio (1968), muy útiles, aunque un tanto picadas por el nacionalismo literario ${ }^{10}$. Lo que sorprende, si leemos el tratado italiano frente al español, es, en el primero, la reducción de la idea a la retórica, al ornatus, y el empleo del término concepto en el sentido restringido de «metáfora». Tesauro tiene una solidez (aristotélica) de pensador no inferior a la de Gracián, y apreciablemente más sistemática: es indudable que la argutezza tiene una extensión más amplia que la agudeza de Gracián, ya que no solo cubre los actos del hombre y cualquier tipo de discurso verbal, sino que se extiende a todo lo existente:

La nozione centrale del trattato è l'argutezza, la quale subito si differenzia dall'acutezza. Quest'ultima è la punta sottile e finissima del pensiero, di cui essa esprime i concetti acuti. Il dominio dell'argutezza è invece immenso, estendendosi ai confini più remoti dell'universo, con conseguenze altrettanto vaste per l'estetica barocca. [...] Quindi non sono soltanto le belle arti (la letteratura, la pittura e la scultura) ad esprimere con le figure e le immagini i pensieri arguti, bensì qualsiasi azione arguta dell'universo,

incluyendo la naturaleza y la metafísica, en un afán de «semiosi illimitata» (Snyder 2005: 107-108) ${ }^{11}$. Es cierto también que «l'autore non riesce mai ad effettuare una scelta netta tra l'argutezza e la metafora, per cui vaste zone del Cannochiale aristotelico s'inscrivono in una struttura discorsiva poliedrica e -nonostante il titolo dell'opera (Dell'arguta et ingeniosa elocutione)-, priva di un unico centro focalizzato sull'elocuzione» (Snyder 2005: 115); pero no es menos cierto que, cuando analiza la metáfora y se ocupa del texto literario, Tesauro se centra fundamentalmente en la elocutio, y a esto debía llevarle también su profunda formación aristotélica. Esto no quita, por cierto, que le dé valor cognitivo a la elocución, es más: valor educativo. Aquí radica una de las expresiones más significativas de la aspiración a unir lo antiguo y lo moderno ${ }^{12}$, y de su preocupación suasoria, que está en la base de su esfuerzo didáctico (enseñar a producir la agudeza, no a gozar de ella).

Tenemos, en fin, un texto claro ante un texto oscuro, y a primera vista confuso, como el de Gracián. Creo que esta percepción se debe en primer

10. Conrieri (2005: 331-333) ofrece una apreciación muy útil del trabajo hecho y por hacer.

11. Todo su capítulo sobre Tesauro merece una atenta lectura.

12. «Tesauro cerca di saldare insieme l'antico e il moderno, o piuttosto di celebrare la modernità della cultura barocca senza abbandonare mai il passato che ne garantisce la legittimità» (Snyder 2005: 111). 
lugar a una perspectiva didáctica ajena a Gracián: lo que el italiano enseña es la retórica, no un pensamiento irracional en su misma concepción como en el tratado espańol. Puede resultar sorprendente el enfoque de Gracián como escasamente preocupado por la pedagogía en su tratado, pero coinciden en ello los mejores lectores recientes. Medítese, por ejemplo, sobre este comentario de Mercedes Blanco: «un jesuita, y por lo tanto pedagogo, como Gracián tenía que sentir como necesario proponer artes y métodos para disciplinar y cultivar la naturaleza. De ahí su afán de inventar un arte de ingenio, pero un arte, observemos, singularmente poco normativo. El arte de ingenio no se compone de reglas. No dice lo que debe hacerse y menos aun lo que se debe evitar» (Blanco, 2006: 28). Tesauro, se ha venido observando tradicionalmente, tiene una preocupación por fijar normas que le distinguen incluso de los otros tratadistas italianos, en particular de Pellegrini, quien no manifiesta una excesiva confianza en la acumulación de reglas. Esto hace que Tesauro tienda a concebir el texto como totalidad, y que se desprenda de sus páginas la importancia del texto poético como unidad. No se confunda esta perspectiva con la agudeza compleja de Gracián (discursos LV y LVI), quien llega a profundizar en textos enteros como una única agudeza, o se encamina hacia la agudeza combinatoria de detectar más agudezas en el mismo texto. La perspectiva didáctica explica también una característica evidente del Cannocchiale, la procedencia de los ejemplos sobre todo del ámbito de la literatura latina y neolatina: el italiano ocupa, con gran diferencia, la segunda posición, y las otras lenguas entran de forma esporádica; por detrás está la ratio studiorum y la educación del manejo de las lenguas vernáculas, incluso en su vertiente literaria, a partir del dominio de las lenguas clásicas, cuyo modelo de aprendizaje normativo y retórico tendrá que aplicarse al romance. Se trata, insisto, de una elección pedagógica ${ }^{13}$, que no supone ninguna jerarquización entre la producción literaria en latín y la italiana, luego no excluye el aprecio por Marino ${ }^{14}$.

13. Subraya el carácter didáctico-retórico de la reflexión de Tesauro respecto a la de Gracián también García Gibert (2013: 493-494). Dicho planteamiento pedagógico es evidente ya en ciertas recomendaciones técnicas (por ejemplo, sobre cómo clasificar las metáforas) y en el empleo de la terminología técnica clásica (de base normalmente griega), de la cual Gracián normalmente prescinde en pro de un léxico propio y de carácter no técnico. Obsérvese lo que se dice sobre el índice categórico en las «cagioni strumentali» (p. 86 y ss. de la edición que tengo en mi biblioteca: Venecia, Benedetto Milocho, 1682). Por otra parte, está claro que antes del capítulo VII «trattato della metafora» el Cannocchiale ofrece, más que un tratado sobre la metáfora, un manual de retórica y estilística, y también el tratamiento de la metáfora termina implicando varias figuras retóricas (morosay precisamentedefinidas), ya quela idea de metáfora deTesauro no esla propiamente retórica -de retórica aristotélica-, sino la de transformación de la realidad mediante la palabra.

14. La escasez de citas y lo genérico de las apreciaciones impiden establecer la proporción Tesauro: Marino = Gracián: Góngora. Entre otras cosas porque, a la altura de la primera edición del Cannocchiale (1655, pero la edición definitiva es de 1670), la estrella de Marino parece haberse eclipsado bastante del horizonte de la poesía italiana, al contrario de lo que ocurre con la tan generalizada aceptación de Góngora en la española. Sobre la fragilidad de la categoría marinismo como marbete interpretativo para toda la poesía barroca italiana ofrece observaciones definitivas Besomi (1969). 
$\mathrm{Si}$, en cambio, el enfoque no es es el de la creación, sino el del resultado logrado, como en el caso de Gracián, resulta necesaria también la cita de textos en romance, expresión de una pluralidad lingüística que resalta la difusión del conceptismo, en un afán de demostrar la extensión universal de los modelos teóricos, más allá de las diferencias contingentes: es lo que captamos todavía en un teórico del barroco extremo, como el ya citado Caramuel, y bien mirado, en cualquier teórico de la literatura, todavía en nuestro tiempo. También las traducciones de Marcial que ofrece Salinas hay que interpretarlas así: pasan, y mucho, de ser meramente instrumentales, y no indican tanto una subordinación (como si de una traducción de servicio se tratara) al texto latino, cuanto un juego en un mismo nivel con los clásicos, en un empeño creativo del todo respetuoso, que se justifica por cierto dentro de la teoría renacentista de la imitación ${ }^{15}$. Lo confirma el que nunca se traduzcan las citas de Guarini (lo cual podía ser útil para los lectores del tratado). Y es más, no falta (V, p. 70) el cotejo entre la traducción de Guarini y otra de Salinas de un dístico de Ausonio Galo: un pequeño certamen traductorium. En la misma perspectiva traductológica hay que interpretar (XXXI, p. 369) la cita de un dístico del Pastor fido directamente de la versión de Suárez de Figueroa.

También puede ser reveladora la comparación entre la Agudeza y la Rhytmica de Caramuel, ya aludida: una asociación que no es novedosa dentro de los estudios gracianos. El gran tratado, que no ha atraído tanto la atención de nuestros contemporáneos como la Metamétrica y sus laberintos de poesía visual tantas veces reproducidos, a pesar de la aparente restricción técnica del horizonte (en principio, es un tratado de métrica románica) reúne también las características de una gran antología, que documenta el gusto y la sensibilidad poética de la segunda mitad del siglo XVII español, ya bastante menos Empty Quarter después de las campañas de exploración realizadas en los últimos años por Alain Bègue y sus colaboradores. Lo que, sin embargo, sobresale de la Rhytmica es la libertad de la palabra poética, que pierde su vinculación con el tema, y adquiere, de forma muy moderna, su completa independencia. El proceso, analizado en otra ocasión (Mazzocchi, 2012), se lleva a cabo gracias a un dominante oggidianismo, o sea (ya en la vertiente de esta corriente filosófica barroca) con la selección de textos del día, sin ninguna preocupación de reconstrucción histórica: Caramuel, como teórico de la poesía, se mueve siempre por la atemporalidad. Considérese que el índice temático (con secciones como Divina, Mariana etc.) no tiene incidencia alguna sobre la organización del tratado, y sirve, fundamentalmente, para fundar con la altura del argumento la licitud de la práctica poética. Añádase, finalmente, que la mayoría de textos seleccionados pertenecen a la poesía religiosa y celebrativa, es decir, una poesía que no transmite ni hechos ni ideas nuevas, sino más bien fórmulas. Desde otra perspectiva, por otra parte, Góngora y las Soledades se enjuician a partir de la idea graciana de Góngora sin secuaces, es decir, inimitable. Con todo, es evidente que Caramuel, al contrario de Gracián (recuérdese el pasaje citado del

15. Vid., por ejemplo, Cuevas Subías (2002). 
Criticón, que rechaza precisamente la infracción del decoro), da con el quid de la modernidad de Góngora, o sea, con la liberación de la poesía del tema.

¿Gracián puede concebir esta independencia entre la palabra y el tema? ¿Puede concebir la ruptura de la Rota Vergilii que Góngora lleva a cabo tan valientemente, desembarazándose de un lastre que las letras llevaban a cuestas desde la antigüedad? Y no me refiero, por supuesto, al valor meramente retórico que esto implica, esto es, la superación definitiva (claro, para la gran literatura, y permitiéndolo todos los clasicismos existentes) del decorum; sino al valor filosófico que esto supone. Rozas evidenció la fuerte presencia del condicionamiento moral en Gracián como recaída significativa en la apreciación de Góngora. Por esto Marino y Lope están representados sobre todo en su faceta de poetas religiosos; se da un "error histórico», como la predilección por Las firmezas de Isabela, no figuran las propuestas más actuales de Quevedo (el existencialismo que individuó en su día Dámaso Alonso), y Gracián omite profundizar en las obras maestras del cordobés. En fin, la Agudeza «es un libro de cómo vivir, en la parcela del decir, más que un tratado puro y desinteresado de retórica y, sobre todo, de sensibilidad poética. En definitiva, tras declarar el valor supremo de las Soledades, las oculta. Tras gustar de Lope y Marino, los falsifica» (Rozas, 1986: 198). Es posible que la interpretación de Rozas sea un tanto excesiva, y que el condicionamiento moralista, sin duda plausible, no afecte tanto al significado como obra de estética de la Agudeza; más en general, creo que nos queda todavía por comprender cómo el jesuitismo pudo asimilar y hacer potable -para empezar desde las cátedras de los colegios- a Góngora. Pero, como siempre, las palabras de Rozas no tienen desperdicio: en efecto, la Agudeza no llega a ser ni un tratado "puro y desinteresado» de retórica ( $\mathrm{y}$ una apreciación de este tenor de un tratado de retórica, cuando todavía nos condiciona el Romanticismo, puede salir solo de una pluma y una cabeza excelentes), ni la expresión de «sensibilidad poética» (afán teorizador y sistematizador incluido), o sea, un Tesauro o un Caramuel.

Lo que es irrebatible es que Gracián no independiza (al menos dentro de las fronteras de su tratado) poesía y concepto, y ni siquiera separa a la poesía del concepto, entendido (según una apreciación filosófica, y no retórica como la de Tesauro) como la facultad del pensamiento humano que se puede manifestar, además de en la poesía, en la prosa y en la proyección extratextual del hombre, en la vida; o sea, en la actio, ya que nos movemos dentro del theatrum mundi y se nos educa para aprovechar en sus tablas todos los recursos expresivos de los cuales como seres humanos disponemos. Lo que resulta del todo ajeno a la visión del mundo de Gracián es el que el valor formal pueda implicar un pensamiento, poseer un valor heurístico en sí. A esto le llevaría también la ya bien asentada difusión del ramismo en los colegios de la Compañía: reduciendo la retórica a la elocutio, el acto intelectual (inventio y dispositio) se independizaba de la misma ${ }^{16}$. Como consecuencia, Gracián por un lado no se

16. Tiene reflexiones muy importantes sobre el ramismo en Gracián (a partir de su contorno jesuítico español) Jorge M. Ayala, en la espléndida introducción a la ed. que utilizamos (cf. n. 2). 
sitúa en la perspectiva del productor del texto, sino en la de sus destinatarios (rechaza, quiero decir, la perspectiva de Tesauro); por el otro, se niega al formalismo extremo de Caramuel (que puede llegar hasta la conversión de la palabra en trazo de dibujo, como en los laberintos ya recordados). Es evidente que todo esto marca (insisto, dentro de las fronteras del tratado, en lo que de condicionante este proyecto textual tiene para el pensamiento) su lectura de Góngora, con la imposibilidad de seguir la propuesta del genio de Córdoba: abandonar la realidad para entrar en otro mundo, el de la palabra poética.

Por todo esto creo que sería una útil herramienta de trabajo (que me comprometo a ofrecer en un plazo razonable) un índice de la Agudeza donde figuren temas y motivos, comparantes y comparados, tanto de los textos citados como de los comentarios que se les dedican. Este índice tendrá, me parece, una utilidad práctica evidente: la Agudeza, en realidad, se desaprovecha como el atlas de la mentalidad y el gusto barrocos que es; pero, además, este índice se abriría hacia un terreno común (el de la rosa, el arroyo, el rubí, o el tiempo, la vida, la sangre...) en el cual Góngora es lectura inevitable. Y si se cotejasen los datos con los de un índice parecido de Tesauro, tendríamos, por una multitud de detalles afines, el universo poético mirado desde el creador (Tesauro) o desde el destinatario (Gracián); es decir, desde una perspectiva retórica (Tesauro), o desde la filosófica (Gracián), aunque siempre con la realidad de por medio. En efecto, tanto desde la retórica, como desde la filosofía, el tema no interesa, mientras que sí lo hace el proceso con el cual se puede captar. Ver cómo se asedia el mismo tema literario desde puntos de vista diferentes, abriría probablemente perspectivas importantes, y Góngora se colocaría en una distancia próxima y remota a la vez, la del poeta que se vale tanto del tema como de la construcción retórica o conceptual alrededor de dicho tema, para llegar al triunfo de la palabra: en último término, sus famosas «metáforas al cuadrado» no vienen a decirnos otra cosa.

\section{Bibliografía}

Besomi, Ottavio, Ricerche intorno alla "Lira» di G. B. Marino, Padua, Antenore, 1969. Blanco, Mercedes, «La idea de estilo en la Espańa del siglo XVII», en Edad de Oro Cantabrigense, Madrid, AISO, 2006, pp. 17-29.

Cancelliere, Enrica, "Góngora y Gracián: teoría y práctica de la metáfora», en Baltasar Gracián: antropología y estética, Berlín, Tramnvía-Frey, 2004, pp. 281-297.

Carreño, Antonio, "Gracián y sus lecturas en el romancero de Góngora», en Actas del IX Congreso de la Asociación Internacional de Hispanistas (1986), Frankfurt am Main, Vervuert, 1989, I, pp. 395-403.

Conrieri, Davide, Scritture e riscritture secentesche, Lucca, Pacini Fazzi, 2005.

Correa Calderón, Evaristo, «Introducción» a Baltasar Gracián, El Criticón, Madrid, Espasa-Calpe, 1971.

Cf. también Blanco (2006: 28): «Gracián adopta una postura formalista y esteticista muy afín a la de las retóricas helenísticas, y la variedad y la intensidad son sus máximos valores». 
Cuevas Subías, Pablo, "Traduciendo a Marcial en la España de 1645: "Leandro" según Manuel de Salinas y Lizana», en Homenaje al profesor Antonio Fontán, AlcañizMadrid, Instituto de Estudios Humanísticos et al., 2002, IV, pp. 1693-1700.

Dehennin, Elsa, "Gracián, Góngora et le Baroque», en Études de philologie romane et d'histoire littéraire offerts à Jules Horrent à l'occasion de son soixantième anniversaire, Liège, s.n., 1980, pp. 613-622.

García Berrio, Antonio, España e Italia ante el conceptismo, Madrid, Anejos de la Revista de Filología Española, 1968.

García Gibert, Javier, «Los fundamentos epistemológicos del conceptismo», en Barroco, Madrid, Verbum, 20132, vol. I, pp. 483-520.

Gracián, Baltasar, El Criticón, ed. de Carlos Vaíllo, Madrid, Círculo de Lectores, 2000. Gracián, Baltasar, Agudeza y arte de ingenio, ed. de Ceferino Peralta, Jorge M. Ayala y José María Andreu, Zaragoza, Prensas Universitarias de Zaragoza-Instituto de Estudios Altoaragoneses-Gobierno de Aragón, 2004.

Gracián, Baltasar Arte de ingenio, Zaragoza, Institución Fernando el Católico, 2005.

Gracián, Baltasar, Arte de ingenio, tratado de agudeza, ed. de Emilio Blanco, Madrid, Cátedra, 20102.

Mazzocchi, Giuseppe, "Caramuel e la poesia spagnola: leggendo la "Rhytmica" , en Un'altra modernità. Juan Caramuel Lobkowitz (1606-1682): enciclopedia e probabilismo, Pisa, ETS, 2012, pp. 111-126.

Monge, Félix, "Culteranismo y conceptismo en la luz de Gracián», en Homenaje. Estudios de filología e historia literaria lusohispanos e iberoamericanos publicados para celebrar el tercer lustro del Instituto de Estudios Españoles, Portugueses e Iberoamericanos de la Universidad Estatal de Utrecht, La Haya, Van Goor Zonen, 1966, pp. 355-381.

Pérez Lasheras, Antonio, "Arte de ingenio y agudeza de arte de ingenio", en Baltasar Gracián. Estado de la cuestión y nuevas perspectivas, Zaragoza, Institución Fernando el Católico, 2001, pp. 71-88.

Poggi, Giulia, «Góngora e l'albero del mistero», Studi ispanici, 1986, pp. 83-122.

Pozzi, Giovanni, «Note prelusive allo stile del Cannocchiale aristotelico», Paragone IV, 1953, pp. 25-39.

Rita, Andreina, «Per un nuovo testimone della Guía espiritual di Miguel de Molinos», en José Ignacio Tellechea Idígoras, El proceso del doctor Miguel Molinos, Roma, Edizioni di Storia e Letteratura, 2005, pp. 99-116.

Roses Lozano, Joaquín, Una poética de la oscuridad. La recepción crítica de las «Soledades», Madrid-Londres, Tamesis, 1994.

Rozas, Juan Manuel, «El compromiso moral en la Agudeza (y en las Poesías varias de Alfay)», en Gracián y su época, Zaragoza, Institución Fernando el Católico, 1986, pp. 191-200.

Senabre, Ricardo, Gracián y el «Criticón», Salamanca, Universidad, 1979.

Snyder, John R., L'estetica del barocco, Bologna, Il Mulino, 2005. 